\title{
Impacto da informatização intra-hospitalar sobre a gestão de custos. Integração da prescrição eletrônica das fórmulas pediátricas e das dietas enterais com suas respectivas áreas de produção
}

\author{
Impact of intrahospital informatization on \\ cost management. Integration of electronic \\ prescription of pediatric formulas and enteral \\ diets with their respective production areas
}

\begin{abstract}
Introduction: Informatization contributes to the integration among various sectors, cost reduction, and improved quality of services. This study aimed to assess the impact on cost/benefit of the integration of electronic prescription of pediatric formulas and enteral diets in the respective production areas in a hospital. Methods: We analyzed the quantitative consumption and financial cost of the products corresponding to $80 \%$ of the budget ceiling for the annual programming of each modality during 2 consecutive months in two steps, i.e., before and after the implementation of the new module. Results: A more effective control of the quantities produced and of the final products dispensed was observed, reducing both the traceable and untraceable demands (an 85\% reduction in financial terms from $R \$ 3770.25 /$ months before to $R \$ 566.73 /$ month after). Conclusion: The change represented a technological innovation that improved the quality of the service provided and contributed to waste reduction.

Key words: Hospital Nutrition Service; cost control; electronic prescription; nutritional therapy.
\end{abstract}

\section{INTRODUCTION}

Within the hospital environment, an appropriate diet can be used as a single therapeutic measure or can be of help for the treatment of diseases, representing an important practice in the fight against the malnutrition of hospitalized patients, which contributes to the increase of complications, morbidity, time of hospitalization, mortality, and the general use of resources $(1,2)$.

The Units of Hospital Food and Nutrition (UHFN), responsible for the nutritional care of patients, have a double responsibility, i.e., to guarantee an adequate supply of food to satisfy the nutritional requirements of the patients and to
Nancy Yukie Yamamoto Tanaka (1) Edgard Monforte Merlo (2)

Carolina Ferreira Nicoletti (3)

Wilson Moraes Góes (4)

Roberta Novaes (4)

Fernando Fávero (4)

Carla Barbosa Nonino (3) Julio Sérgio Marchini (3)

1) Division of Nutrition and Dietetics. University Hospital, Faculty ofMedicineofRibeirãoPreto, University of SãoPaulo, RibeirãoPreto, SãoPaulo, Brazil.

(2) Faculty of Economics and Administration of Ribeirão Preto. University of São Paulo, Ribeirão Preto, São Paulo, Brazil. (3) Department of Internal Medicine, Faculty of Medicine of Ribeirão Preto University of São Paulo, Ribeirão Preto, São Paulo, Brazil. (4) Center of Information and Analysis. University Hospital, Faculty ofMedicine of RibeirãoPreto, University ofSãoPaulo, RibeirãoPreto, SãoPaulo, Brazil.

Corresponding author: Nancy Yukie Yamamoto Tanaka Division of Nutrition and Dietetics. University Hospital Faculty of Medicine of Ribeirão Preto University of São Paulo, Ribeirão Preto São Paulo, Brazil Avenida dos Bandeirantes, 3900. Ribeirao Preto SP, Brazil, Zip code: 14049-900 Phone: 55163602134 Email: nancyyyt@hotmail.com

Este trabajo fue recibido el 25 de Mayo de 2014 y aceptado para ser publicado el 5 de Enero de 2015. control the entire process of production and distribution. Thus, nutritional assistance should be provided by incorporating concern about reduced costs and by considering the importance of the management of food waste as a contribution to this purpose.

Food residues are due to the lack of full or partial acceptance of diets and formulas (pediatric formulas, nutritional supplements and enteral nutrition) by the patients and intact leftovers are caused by inadequate production and distribution of the diets, such as incorrect collection of medical prescriptions by nutrition assistants, lack of adjustment of the dietary prescriptions to the medical prescriptions, and 
their faulty delivery to patients discharged from the hospital, or with a prescribed fast, or patients who have died (3). Considering the limitation of the management of food leftovers due to clinical, dietary and psychological factors that interfere with the acceptance of the prescribed diet and/or formula by the patient, a strategy for the reduction of intact leftovers should include a more rapid communication between the admitting units and the UHFN (4) and the elimination of human errors.

In the hospital units, patient care has a dynamic characteristic, requiring constant attention on the part of the multidisciplinary tem. Thus, in order to insure the quality of care, the supporting services must carry out their activities in such a way as to promptly satisfy the needs of their patients without compromising the work of other professionals.

In the areas of pediatric formula and enteral diet production, the introduction of processes that obviate the need for intermediate agents for the request of formulas in cases of admission to the hospital, changes of bed, deviations or faults due to human errors, permits an independent, functional and faster work flow.

Informatization regarding the integration of electronic prescription with the production areas may represent a way to improve the flow of the process ranging from the prescription of nutritional therapy to distribution of the diets to hospitalized patients. This would insure the quality and efficiency of nutritional care, providing a greater control of the diets and formulas produced and distributed by rationalizing the use of manpower, the rapid processing of information and the integration between various sectors.

The objective of the present study was to assess the impact caused by the integration of the electronic prescription of pediatric formulas and enteral diets with their respective production areas on the costs and benefits observed in the management of processes, including the consumption of food products and the final financial expenditure.

\section{METHODOLOGY}

A longitudinal study was conducted in the Pediatric Formula and Enteral Diet production sector of the University Hospital devoted to assistance, teaching and research with 696 activated beds for tertiary care. The study was directed in two steps consisting of the phase preceding (phase 1) and following (phase 2) the implementation of a new module that integrated the electronic prescription of nutritional therapy with these areas of production.

The implantation of informatics included the installation of a microcomputer, a laser printer, a thermal printer and a bar code reader in the sector of production and dispensing of Pediatric Formulas and Enteral Diets. Approximately one microcomputer per 10 beds was made available on the inpatient units and connected to the data base managing unit by means of the electronic prescription system.

The Standardization of Routine and Specialized Diets, of Pediatric Formulas and of Enteral Nutrition Formulas was used for the elaboration of the Program of Electronic Prescription of Nutritional Therapy, with a single code being established for each type of diet. This permitted the system to calculate the total amount of the diets to be produced and delivered, the identification of the formulas, diets and preparations, and the control of dispensation to the inpatient units.

Phase 1 included May and June 2007 and phase 2 included August and September 2008. The products used for the preparation of formulas (real and ideal consumption of these products), medical prescriptions, and traceable and untraceable demands were evaluated and the financial expenditure was surveyed in both phases.

The consumption of products (pediatric formulas and enteral diets) corresponding to $80 \%$ of the budget ceiling of the annual programming of each modality at the beginning of the study was analyzed. The products were: 1st semester infant formula, semi-elemental infant formula, standard polymeric enteral diet, enteral diet containing fibers, enteral diet for diabetic patients, and semi-elemental enteral diet.

The real consumption of the products used for the preparation of pediatric formulas and enteral diets was analyzed on a monthly basis and compared to the ideal consumption determined by the demands. Real consumption was calculated according to the quantity of products used by the section based on the records of entry and exit of each item in the Storage Section. Ideal consumption was calculated based on the quantity of products needed to fill out the medical prescriptions and to meet the traceable demands.

The medical prescriptions of pediatric formulas and enteral diets elaborated during the two consecutive months of each phase were analyzed considering that the valid prescription is always the last one, with repeated prescriptions or prescriptions canceled by a later one being eliminated.

Traceable and untraceable demands were assessed. Traceable demands were those originating from production manually recorded in order to supply the outpatient clinic, extra requests, and safety margin (a maximum of 15\% for pediatric formulas and of $10 \%$ for enteral diets). Untraceable demands were those determined by the difference between real consumption and consumption generated by the medical prescriptions and by the traceable demands, characterizing an uncontrolled consumption.

Finally, a survey was performed of the financial expenditure concerning the food products (real consumption) and of the expenditure related to untraceable demands, based on the current unit value (in Reais) present in the financial consultation of the hospital under study.

\section{Statistical analysis}

Descriptive analysis of the data was performed, followed by the Student t-test in order to compare the financial expenditure data in terms of the number of medical prescriptions of pediatric formulas and enteral diets collected in Phases 1 and 2 and between years. The SAS 8.0 software was used for all analyses, with the level of significance set at $p<0.05$.

\section{RESULTS}

The monthly analysis of the real consumption of the products used for the preparation of pediatric formulas and enteral diets, with comparison to the ideal consumption determined by the demands during the two phases, is presented in table 1.

During phase 1, was detected a greater losses for almost all variables, which means that the produced formulas exceeded the ideal consumption and showed a need for intervention in the management of formula production was detected in order to minimize or eliminate untraceable demands. Whereas during phase 2, a greater control of the quantities produced was observed regarding most of the items analyzed, i.e., the number of delivered formulas was the same as the ideal one.

During phase 2, the real consumption of most products was equal to the ideal consumption, demonstrating the efficiency and the impact of informatization on the management 
and control of food products, generating a better performance in terms of costs. The food products used for the preparation of formulas produced in smaller quantities showed a more effective control. Conversely, a similar result was not observed for the 1st semester infant formula or the standard polymeric enteral diet, which are more commonly used. These products are not only used on the wards but also at the ambulatory level (polymeric enteral diets) and in the Obstetrical Center (1st semester infant formula replacing maternal milk). At the time of the study, these two centers were not informatized, a situation that represented a limiting factor of the study.

Considering the financial expenditure (total and with untraceable demands), there was a significant reduction of approximately $85 \%$ of costs related to untraceable demands from $R \$ 3,770.25$ in 2007 to $R \$ 566.73$ in 2008 . The mean monthly values are presented in table 2 .

The number of prescriptions and the expenditures with untraceable demands differed significantly in relation to the years, although there was no difference in total expenditure (related to the cost of products involved in real consumption) between 2007 and 2008.

An increase in the number of prescriptions of pediatric formulas and enteral diets was observed in phase 2, without the occurrence of increased financial expenditures with food products in order to fill out these prescriptions. A difference in expenditure with untraceable demands was observed between 2007 and 2008.

\section{DISCUSSION}

The present data support the affirmation that information technology can contribute to improved patient safety $(5,6)$. Informatics and automation of pharmaceutical services function as important tools for the optimization of activities, reducing the time of execution and improving quality. In addition, they guarantee a lower rate of medication errors and facilitate other activities such as pharmacovigilance and pharmacoepidemiology, also permitting a rational use of medications (7). Other studies have reported the use of information technology as an effective mechanism for providing better patient safety, with a reduction of medication errors (8-10).

The present results show that the application of information technology by integrating the electronic prescription of pediatric formulas and enteral diets with their respective production areas brought about cost benefits and improved the quality of the service provided.

The Standardization of Routine and Specialized Diets, of Pediatric Formulas and of Enteral Nutrition existing in the Food and Nutrition Unit of the hospital was used for the elaboration of the Program of Electronic Prescription of Nutritional Therapy, with a single code being established for each type of diet, in order to permit the system to determine the total diets to be produced and delivered, the identification of the formulas, diets and preparations, and the control of dispensing to the wards.

On this basis, the system permits formula identification

\section{TABLE 1}

Real consumption versus ideal consumption of products used in the areas of production of pediatric formulas and enteral diets.

\begin{tabular}{|c|c|c|c|c|c|c|}
\hline Material & Unit & $\begin{array}{c}\text { Real } \\
\text { consumption }\end{array}$ & $\begin{array}{c}\text { Prescritions } \\
\text { (a) }\end{array}$ & $\begin{array}{l}\text { Traceable } \\
\text { demands } \\
\text { (b) }\end{array}$ & $\begin{array}{c}\text { Ideal } \\
\text { consumption*** } \\
(a+b)\end{array}$ & $\begin{array}{c}\Delta \text { percent } \\
\text { consumption } \\
\text { (Real } x \text { Ideal) }\end{array}$ \\
\hline \multicolumn{7}{|c|}{ 1st Semester infant formula } \\
\hline Phase 1 & Can* & 369 & 195 & 91 & 286 & $22 \%$ \\
\hline Phase 2 & Can* & 396 & 217 & 89 & 306 & $23 \%$ \\
\hline \multicolumn{7}{|c|}{ Semi-elemental infant formula } \\
\hline Phase 1 & Can* & 234 & 203 & 19 & 222 & $5 \%$ \\
\hline Phase 2 & Can* & 119 & 97 & 22 & 119 & 0 \\
\hline \multicolumn{7}{|c|}{ Elemental infant formula } \\
\hline Phase 1 & Can* & 73 & 60 & 3 & 63 & $14 \%$ \\
\hline Phase 2 & Can* & 18 & 18 & 0 & 18 & 0 \\
\hline \multicolumn{7}{|c|}{ Polymeric enteral diet } \\
\hline Phase 1 & Diet $^{* *}$ & 8.652 & 7.054 & 1.201 & 8.255 & $5 \%$ \\
\hline Phase 2 & Diet** & 11.124 & 9.283 & 1.602 & 10.885 & $2 \%$ \\
\hline \multicolumn{7}{|c|}{ Enteral diet with fiber } \\
\hline Phase 1 & Diet $^{* *}$ & 2.038 & 2.014 & 24 & 2.038 & 0 \\
\hline Phase 2 & Diet $^{* *}$ & 2.574 & 2.352 & 222 & 2.574 & 0 \\
\hline \multicolumn{7}{|c|}{ Enteral diet for diabetes } \\
\hline Phase 1 & $\operatorname{Diet}^{* *}$ & 1.746 & 1.209 & 122 & 1.331 & $24 \%$ \\
\hline Phase 2 & Diet $^{* *}$ & 1.773 & 1.657 & 116 & 1.773 & 0 \\
\hline \multicolumn{7}{|c|}{ Semi-elemental enteral diet } \\
\hline Phase 1 & Diet $^{* *}$ & 867 & 815 & 47 & 862 & $1 \%$ \\
\hline Phase 2 & Diet $^{* *}$ & 1.116 & 1.010 & 106 & 1.116 & 0 \\
\hline
\end{tabular}

Source: Storage Section of Food and Nutrition Unit of the hospital (2007 and 2008); *400 gram can;

${ }^{* *}$ Diet with 300 kilocalories; ${ }^{* * *}$ Ideal consumption $(a+b)=$ prescriptions $(a)+$ traceable demands $(b)$ 
and the elaboration of a production order based on the prescription of nutritional therapy by determining the total quantities of each type of prescribed formula. In addition, it identifies newly admitted patients or patients who are starting to use the diets, so that time points preceding the period of validity established in the program (18:00 to $17: 00 \mathrm{~h}$ of the subsequent day for pediatric formulas and 21:00 to 20:00 $\mathrm{h}$ of the subsequent day for enteral diets) will be generated, permitting immediate filling of the prescription. This change eliminated human errors at the time of collection or transcription of data to the registry and failure to cancel the formulas due to suspended prescription, patient discharge or death, factors responsible for leftover formulas on the wards, with consequent waste.

The prescriptions issued after 13:00 h, the time established for the electronic elaboration of the production orders, are verified and the system permits the visualization of the two prescriptions (the current one and the previous one), so that the following steps may be taken: the alteration can be cancelled when the formulas are identical or involve very close volume modifications that do not justify new manipulation; the alteration can be classified as re-work when it only requires extra manipulation and the generation of new identification labels, with a new order of production being sent in order to complete the volume; or can be recorded as waste when the modification does not permit reuse of the previous formula, with the new production order being sent.

With this, the system permitted an effective control of the formulas delivered to the wards and their respective production, with traceable demands being limited to ambulatory care, and of the safety margin that did not always reach the established percentage.

The order of production generated by the electronic system in real time permitted a change in the planning and control system in such a way that the production, previously estimated based on the consumption of the preceding day, which can be called "push planning and control system" whereby the estimated demand is responsible for the determination of the quantity to be produced, was shifted to a system known as "pull planning and control system", in which it is the demand that generates the production (11). This inversion in the way of generating production permitted an effective control compared to estimate-based production, which involved more waste.

The electronic dispensing of formulas using a bar code and their delivery to the wards, accompanied by the respective lists that confirm delivery, eliminated undue solicitations, avoiding duplicate work to meet the same demand. The notification of discharges, fasting and deaths by the system prevents the delivery of these formulas to the wards, reducing waste by permitting reuse of the formulas when possible.

The identification of patients who are starting to use the formulas permitted an immediate supply (for the next scheduled time) without the need for a request on the part of the nursing or nutrition team, representing a considerable improvement of the care for hospitalized patients.

The implementation of the new module also led to improvement of the financial aspects because of the greater control and the consequent reduction of previously existing waste.

In practice, a faster and more precise handling of pediatric formulas and enteral diets was detected, without the need for solicitation on the part of the nursing team, with a reduction of the number of telephone calls. This fact, associated with the beginning of formula dispensation using a bar code, reduced the number of complaints and the wastage on the wards.

\section{CONCLUSION}

The informatization process provided important resources that permitted a better rationalization of work and effective control of product consumption, of the quantity produced and of formula dispensing. These aspects, together with the rapid availability of information provided by the system, contributed to the improvement of the care provided to hospitalized patients.

\section{RESUMEN}

Introducción: La informatización contribuye para la integración entre distintos sectores, la reducción de costes y la mejora de la calidad de los servicios. Este estudio tuvo como objetivo evaluar el impacto sobre los costes y beneficios que ofrece la integración de la receta electrónica de formulaciones pediátricas y la alimentación enteral con sus respectivas zonas de producción de un hospital. Métodos: Se analizaron el consumo cuantitativo y financiero de los productos correspondientes al $80 \%$ del límite máximo del presupuesto de la programación anual de cada modalidad durante 2 meses consecutivos en dos etapas, antes y después de la implementación del nuevo módulo. Resultados: Hubo un control más efectivo de las cantidades producidas, dio a conocer los

\section{TABLE 2}

Comparison of the financial expenditures and of the prescriptions between years 2007 and 2008.

\begin{tabular}{lcccc}
\hline Variable & Year & Means & Differences & $95 \% \mathrm{Cl}$ \\
$\begin{array}{lccc}\text { Number of } \\
\text { prescriptions }\end{array}$ & 2007 & $2,586.00$ & & \\
Total & 2008 & $3,907.50$ & $-1,321.50$ & $(-2,561.35 ;-81.67)$ \\
& 2007 & $R \$ 45,333.73$ & & 0.04 \\
Expenses with & 2008 & $R \$ 38,092.90$ & $R \$ 7,240.83$ & $(-10,972.09 ; 5,453.76)$ \\
untraceable demands & 2007 & $R \$ 3,770.25$ & & 0.23 \\
& 2008 & $R \$ 566.73$ & $R \$ 3,203.52$ & $(2,590.27 ; 3,816.72)$ \\
\hline Difference between years calculated by the Student t-test. & & & 0.0028 \\
\hline
\end{tabular}


productos finales, reduciendo las demandas tanto trazables y no rastreables (reducción de $85 \%$ en términos financieros, de $\mathrm{R} \$ 3770,25$ / mes por adelantado y $\mathrm{R} \$ 566,73$ / mes más tarde). Conclusión: El cambio representó una innovación tecnológica que proporciona una mejor calidad de servicio y ha contribuido a la reducción de residuos.

Palabras clave: servicio de nutrición del hospital; control de costes; prescripción electrónica; terapia nutricional.

\section{REFERENCES}

1. Correia MI, Waitzberg DL. The impact of malnutrition on morbidity, mortality, length of hospital stay and costs evaluated through a multivariate model analysis. Clin Nutr 2003; 22(3):235-9.

2. Norman K; Pichard C.; Lochs H.; Pirlich M. Prognostic impact of disease-related malnutrition. Clin Nutr. 2008; 27(1):5-15.

3. Nonino-Borges CB, Rabito El, Silva K, Ferraz CA, Chiarello $P G$, Santos JS, Marchini JS. Desperdício de alimentos intrahospitalar. Rev Nutr. 2006; 19(3):349-56.

4. Barton AD, Beigg CL, MacDonald IA, Allison SP. High food wastage and low nutritional intakes in hospital patients. Clin Nutr. 2000; 19(6):445-9.
5. Pagano M, Gauvreau K. Princípios de Bioestatística. São Paulo: Editora Thomson, 2004.

6. Bates DW, Gawande AA. Improving safety with information technology. N Engl J Med. 2003; 348:2526-34.

7. Serafim SAD, Forster AC, Simões MJS, Penaforte TR. Assessment of informatization for the dispensing of medications at a university hospital. Clinics 2010; 65(4):417-24.

8. Pepper GA. Errors in drug administration by nurses. Am J Health Syst Pharm. 1995; 52: 390-5.

9. Delgado Sánchez O, Escrivá Torralva A, Vilanova Boltó M, Serrano López de lãs Hazas J, Crespi Monjo M, Pinteño Blanco M, Martínez López I, Tejada González P, Cervera Peris M, Fernández Cortés F, Puigventós Latorre F, Barroso Navarro M.A. Estudio comparativo de errores con prescripción electrónica versus prescripción manual. Farm Hosp. 2005; 29(4):228-35.

10. Bates DW, Teich JM, Lee J; Seger D, Kuperman GJ, Ma'Luf, $\mathrm{N}$; et al. The impact of computerized physician order entry on medication error prevention. I Am Med Inform Assoc. 1999; 6(4):313-21.

11. Slack N, Chambers S, Johnston R. Administração da produção. Tradução Maria Teresa Corrêa de Oliveira; Fábio Alher. 2 ed. São Paulo: Atlas, 2002. 